NBER WORKING PAPER SERIES

\title{
TAXATION OF INTEREST INCOME
}

Roger H. Gordon

Working Paper 9503

http://www.nber.org/papers/w9503

\section{NATIONAL BUREAU OF ECONOMIC RESEARCH 1050 Massachusetts Avenue \\ Cambridge, MA 02138 \\ February 2003}

I would very much like to thank Joan Muysken and Soren Bo Nielsen as well as two referees for comments on an earlier draft. The views expressed herein are those of the authors and not necessarily those of the National Bureau of Economic Research.

C2003 by Roger H. Gordon. All rights reserved. Short sections of text not to exceed two paragraphs, may be quoted without explicit permission provided that full credit including notice, is given to the source. 
Taxation of Interest Income

Roger H. Gordon

NBER Working Paper No. 9503

February 2003

JEL No. H21

\begin{abstract}
Why is interest income taxed more heavily than other forms of capital income? This differential tax treatment has generated substantial tax arbitrage, resulting in lower tax revenue, efficiency costs, and apparently net gains to rich borrowers and net losses to poor lenders, together suggesting that this tax treatment makes no sense on welfare grounds.

In examining this argument more formally, this paper reveals two omitted considerations that can help explain the existing tax treatment. First, the forecasted increase in the market interest rate results in a redistribution from rich borrowers to poor lenders. Yet this redistribution comes at no marginal efficiency cost, starting from a situation with no distortions to portfolio choice, so at the margin dominates further redistribution through the income tax.
\end{abstract}

In addition, information about an individual's portfolio choice reveals information about her earnings ability, even controlling for observed labor income, if those who are more able tend to be less risk averse. By making use of this extra information about earnings ability, the tax system can be better tailored to redistribute from able to less able, for any given efficiency cost.

Roger H. Gordon

Department of Economics

University of California, San Diego

9500 Gilman Drive

La Jolla, CA 92093-0508

and NBER

rogordon@ucsd.edu 


\title{
Taxation of Interest Income
}

\author{
Roger H. Gordon
}

Under existing tax law, income from bonds faces a higher effective tax rate than income from virtually any other financial or real asset, since the entire nominal return is fully taxable. The resulting tax arbitrage leads to those in high tax brackets borrowing heavily to buy more lightly taxed assets, while the bonds issued end up being owned by those in lower or zero tax brackets. As documented by Gordon and Slemrod (1988) using U.S. data for 1983, corporations and richer individuals saved enough in taxes on their large net interest deductions to offset essentially all corporate and personal income taxes collected on all other forms of income from capital. At least ignoring implications for the market interest rate, the existing tax treatment of interest income/payments seems to generate not only a large revenue loss and large distortions to portfolios, but also perverse distributional effects, with corporations and the rich saving substantially on taxes through their interest deductions and the poor paying taxes on their positive interest income.

As a result, the existing tax treatment of interest income and payments certainly seems very puzzling. Why is this tax treatment so common across countries, and so stable over time? It is not for lack of proposals to change it. ${ }^{1}$

The objective of this paper is to examine more closely the optimal tax treatment of interest income, to see whether the current tax treatment is as perverse as portrayed above. The intuition we start with, following Atkinson and Stiglitz (1976), is that commodity taxes should provide no net welfare gain when nonlinear income taxes are also available, as long as the utility function is weakly separable between leisure and consumption. In particular, this result suggests that income from savings should not be taxed, since such a tax is equivalent to a commodity tax on future consumption. Following Atkinson and Stiglitz (1976), we examine the welfare effects of including a small fraction of net interest income in the personal tax base, starting from an optimal nonlinear tax on observed labor income.

I would very much like to thank Joan Muysken and Soren Bo Nielsen as well as two referees for comments on an earlier draft.

1 See for example U.S. Treasury (1984), which focused heavily on limiting the amount of tax arbitrage using debt, in part by proposing to tax real rather than nominal interest income. 
Contrary to the initial intuition, the model does forecast that net interest income should enter the tax base. The model describes two sources of potential welfare gain from this tax treatment. First, a marginal shift from labor income taxes to taxes on net interest income causes the market-clearing interest rate to rise. Given the observation in the data that the poor are net creditors and the rich net debtors, this rise in the interest rate provides a net transfer from rich to poor. While further such transfers from rich to poor through the income tax come at the price of higher distortion costs sufficient to leave welfare unaffected at the margin, introducing small portfolio distortions provides distributional gains with no marginal efficiency costs. ${ }^{2}$

Second, even conditional on observed labor income, observed bond holdings can well provide information about an individual's underlying ability. By making use of this information, the tax system can better approximate a tax on unobserved ability. ${ }^{3}$ Formally, we assume that, for any given observed value for labor income, those who are more able are less risk averse, plausibly because they have a larger reserve of potential earnings available as a reserve to help absorb losses. As a result, the less able hold more bonds and less equity, everything else equal. While the forecasted result from including net interest income in the tax base is the same type of tax arbitrage seen in the data, the model also implies that the resulting increase in the market interest rate is sufficient that the beneficiaries of this arbitrage are largely the less able lenders, with the most able borrowers left largely unaffected.

The paper concludes with a brief set of conclusions.

\section{Taxation of interest income}

The economy consists of $I$ individuals, who potentially differ in their assets, their wage rate, their taste for leisure, and their degree of risk aversion. The role of the tax system

\footnotetext{
2 See Naito (1999) for a similar result, where small commodity taxes favoring (penalizing) industries employing primarily low (high) skilled workers yield distributional gains through changes in relative wage rates, at the margin with no offsetting efficiency costs.

3 See Saez (2002) for a more general demonstration that commodity taxes may be appropriate whenever consumption of a good is correlated with the social marginal utility of income at any given level of observed labor income.
} 
is to collect revenue in an equitable fashion in order to finance government expenditures. Distorting rather than lump-sum taxes should be used only if they improve the distribution of utilities. By assumption, the more able (those with a higher potential wage rate) are viewed to have higher utility, regardless of the degree to which they spend their potential income on leisure vs. goods. However, the government does not observe ability, only labor income. As in Mirrlees (1971), it then designs some nonlinear tax on labor income, trading off the distributional gains with the implied efficiency losses from distortions to labor supply decisions.

Atkinson and Stiglitz (1976) then show that if the utility function is separable between leisure and consumption then there would be no distributional gain yet an efficiency loss from introducing commodity taxes. Given this separability, consumption patterns simply depend on observed labor income, so provide no additional information about underlying ability. Using a narrower tax base, through use of commodity taxes, then introduces additional distortions without any potential distributional gains.

Since future vs. current consumption are examples of different consumption goods, higher tax rates on future vs. current consumption would then be inappropriate. Following this argument, we will ignore general taxes on the return to savings.

Is there a case, though, for including net interest income, at least to some degree, in the personal income tax base? By the Atkinson and Stiglitz (1976) argument, there are no such grounds if an individual's net demand for bonds is simply a function of labor income, since then a tax on labor income provides the same distributional effect without introducing further distortions. However, portfolio choice also depends on an individual's degree of risk aversion. If the degree of risk aversion is correlated with the individual's wage rate, conditional on observed labor income, as we will argue should be expected, then there will be grounds for making use of a tax (or subsidy) on net interest income, in order to better link an individual's tax payments to her underlying ability. Our objective will be to explore the nature of the optimal tax treatment of net interest income.

In order to develop this argument, assume that individual $i$ has financial assets of $F_{i t}$ at date $t$ but also receives a flow of potential income equal to $w_{i t} T-\tau_{t}\left(w_{i t} T\right)$ each period, where $T$ is the maximum time available in a period, $w_{i t}$ is individual $i$ 's wage rate, and 
$\tau_{t}($.$) represents the nonlinear tax schedule on labor income. For simplicity, we assume that$ this flow of potential net-of-tax labor income is nonstochastic. ${ }^{4}$ If the after-tax real interest rate equals $\theta_{i t} r$, then the present value of this flow of potential labor income equals

$$
H_{i t} \equiv \int_{s=t}^{\infty}\left[w_{i s} T-\tau_{s}\left(w_{i s} T\right)\right] e^{-\theta_{i s} r} d s .
$$

Total assets then equal $A_{i t} \equiv F_{i t}+H_{i t}$. The income from these assets will finance the purchase of a vector of consumption goods each period $s$, where this vector includes leisure as well as goods and services.

The individual can invest the financial assets $F_{i t}$ in either equity or bonds, where the return on equity is risky but where for simplicity the return on bonds is riskless. Let the amount of equity purchased be denoted by $S_{i t}$ and that of bonds by $B_{i t}$. Implicitly, however, the individual is investing her entire wealth, $A_{i t}=F_{i t}+H_{i t}$, in equity and bonds. While her total equity investments remain equal to $S_{i t}$, her total bond investments implicitly equal $B_{i t}+H_{i t}$. Let $s_{i t}\left(b_{i t}\right)$ denote the fraction of the total portfolio invested in equity (bonds), so that $s_{i t}=S_{i t} / A_{i t}$ and $b_{i t}=1-s_{i t}$.

Since the aggregate holdings of bonds in the economy are zero (for every lender there is a borrower), we know that $\sum_{i} F_{i t}=\sum_{i} S_{i t} .{ }^{5}$ Therefore, aggregate equity investments are immediately determined given aggregate financial assets. Our focus, though, will be on the portfolio composition of different investors.

4 Following the labor contracting literature, the firm's equity holders can more cheaply bear the risk from the firm than can its workers, so that the cost of labor to the firm is minimized if workers are provided a nonstochastic wage. While in general, introducing a stochastic wage will introduce computational difficulties, Merton (1990, pp. 147-9) shows that results generalize without substantive changes under particular assumptions. In particular, the present value of future labor income is simply replaced by the discounted present value of the certainty-equivalent of future labor income. In addition, if the random process in labor income is correlated with the random return on some financial assets, these financial assets can be used as a hedge, altering portfolio choice accordingly. Such an added link between portfolio choice and observed labor income would not introduce any qualitative change to our analysis, however, since the link with unobserved ability would remain present.

5 We implicitly assume here that all borrowers and lenders are individuals, so ignore both government borrowing and firm borrowing. Including these additional forms of borrowing would require modeling how the amount of government and firm borrowing changes in response to changes in the tax treatment for individuals, and the resulting change in market interest rates. Corporate borrowing incentives would remain unaffected, though, if the corporate tax rate equals $\tau_{w t}^{\prime}$, as defined below, so that a firm's after-tax interest rate remains unaffected. The government's cost of borrowing remains unaffected as well if the average tax rate faced on the additional bond holdings again equals $\tau_{w t}^{\prime}$. The pattern of these additional bond holdings depend on who bears the added taxes in the future to repay this debt. While some changes in firm and government incentives, so in their behavior, are inevitable, the qualitative results in the paper would remain unaffected. 
The return on stocks is stochastic, and follows the stochastic process:

$$
\frac{d S}{S}=g d t+\sigma d z
$$

where $g$ is the expected return on equity, $d t$ captures any nonstochastic time trends and $d z$ represents continuous Brownian motion with standard deviation $\sigma$. Within the model, the return on equity is untaxed. Our focus will be on the desired tax treatment of interest income/payments. ${ }^{6}$ To begin with, however, we should note that a uniform tax rate on both interest income and interest payments collects zero revenue and has no effect on incentives. Since the aggregate supply of bonds to the economy is zero, aggregate interest income and aggregate interest payments are equal in size, so that revenue from taxes on interest income would be exactly offset by the revenue loss from interest deductions. In addition, the pretax interest rate would adjust so that the after-tax interest rate is unaffected by the tax for all individuals.

Following current tax provisions, however, we assume that the potential tax rate on net interest income is proportional to the individual's marginal tax rate on labor income. In particular, consider letting the individual's actual income tax payments equal $\tau_{t}\left(w_{i t} h_{i t}+\right.$ $\left.\mu_{t} r B_{i t}\right)$, where $h_{i t}$ equals actual hours of work. The resulting net-of-tax marginal interest rate faced by individual $i$ is then $\left(1-\mu_{t} \tau_{i t}^{\prime}\right) r$, so that by assumption $\theta_{i t}=\left(1-\mu_{t} \tau_{i t}^{\prime}\right)$. The rate of return on bonds is assumed to be nonstochastic, and then equals

$$
\frac{d B}{B}=\theta_{i t} r_{t} d t
$$

Our focus will be on whether the optimal $\mu_{t}$ is nonzero, and if so its optimal sign.

For simplicity, we will ignore the general equilibrium effects of a change in capital investment on factor and consumer prices by assuming a linear technology. The wage rate at a given skill level will be the numeraire, and all skill levels are assumed to be perfect

\footnotetext{
6 More generally, our focus is on the differential tax treatment of debt and equity. In particular, a uniform tax on all asset income will not distort portfolios. (This assumes that the risk transferred to the government through random tax payments is ultimately returned to shareholders. See Gordon (1985) for further discussion.) By normalizing taxes on equity income to zero, we will examine whether taxes on debt should be nonzero.
} 
substitutes. $^{7}$ Given this linear technology and the fixed wage rates, the return to equity remains fixed as well.

Denote the rate of consumption expenditures (on leisure as well as goods and services) at time $t$ by consumer $i$ by $C_{i t}$. This consumer's indirect utility from the flow of consumption at date $t$ is denoted by $V\left(C_{i t} ; w_{i t}, \mathbf{p}_{t}\right)$, where $\mathbf{p}_{t}$ represents the vector of consumer prices. Specifically, assume that

$$
V\left(C_{i t} ; w_{i t}, \mathbf{p}_{t}\right)=f\left(w_{i t}, \mathbf{p}_{t}\right) \frac{C_{i t}^{1-\gamma_{i}}}{1-\gamma_{i}}
$$

where $\gamma_{i}$ represents the coefficient of relative risk aversion, and where $\gamma_{i}>0$ to capture risk aversion. The present value of expected utility equals

$$
W_{i t}=\mathrm{E}_{0} \int_{s=t}^{\infty} e^{-\rho(s-t)} V\left(C_{i s} ; w_{i s}, \mathbf{p}_{s}\right) d s
$$

where $\rho$ is the individual's utility discount rate.

Formally, we will assume that individuals differ in their degree of risk aversion, and that those with higher values of lifetime potential labor income tend to have a lower value of $\gamma_{i}$. However, this utility function can be taken to be a local approximation to a more general function, shared by individuals, in which the degree of risk aversion is itself a declining function of the individual's value of $C_{i t}$.

Individuals choose their portfolio allocation at each point in time as well as their consumption rate to maximize their expected utility as defined in equation (3). By Ito's lemma, we can take a second-order Taylor approximation of an individual's utility, so that the optimization problem can be reexpressed as ${ }^{8}$

$$
W_{i t}=\max _{\{C, b, s\}} E_{0}\left\{W_{i t}+V\left(C_{i t} ; w_{i t}, \mathbf{p}_{t}\right)-\rho W\left(A_{i t}\right)+W^{\prime}\left(A_{i t}\right) d A_{i t}+.5 W^{\prime \prime}\left(A_{i t}\right) d A_{i t}^{2}\right\}
$$

Here, $d A_{i t}$ represents the change in the individual's real wealth over time. Decisions are made subject to the individual's budget constraint that $b_{i t}+s_{i t}=1$.

\footnotetext{
7 Without this assumption, various other supplementary taxes/subsidies can be justified. See Naito (1999) for further discussion.

8 We follow closely here the derivation used in Merton (1990).
} 
At any interior optimum for portfolios, increasing $s_{i t}$ and decreasing $b_{i t}$ to compensate has no effect on utility at the margin, implying that ${ }^{9}$

$$
g-\theta_{i t} r=\gamma_{i} s_{i t} \sigma^{2}
$$

yielding a conventional expression for the risk premium on equity. Therefore, $s_{i t}$ varies across individuals only to the extent that $\theta_{i t}$ or $\gamma_{i}$ varies. In particular, $s_{i t}$ takes on a high value for those with low values of $\theta_{i t}$ and/or $\gamma_{i}$.

Consider first the outcome with $\mu_{t}=0$, and so $\theta_{i t}=1$. We will then explore how welfare changes as the government deviates from this choice.

If $\mu_{t}=0$ and if all individuals have the same $\gamma_{i}$, then the model forecasts that all individuals have the same fraction, $s$, of their overall assets $A_{i t}$ invested in equity. With $S_{i t} / A_{i t}=s$, we infer that ${ }^{10}$

$$
\frac{S_{i t}}{F_{i t}}=s\left(1+\frac{H_{i t}}{F_{i t}}\right)
$$

and

$$
\frac{B_{i t}}{F_{i t}}=(1-s)-s \frac{H_{i t}}{F_{i t}} .
$$

In particular, those with high potential future earnings relative to their financial assets will have a higher fraction of their financial assets invested in equity, and therefore a lower fraction invested in bonds. Those with a relatively high value of $H_{i t} / F_{i t}$ will therefore be in debt while those with a relatively low value of $H_{i t} / F_{i t}$ will have positive bond holdings. Not surprisingly, the young will therefore be in debt, since their current financial assets are small relative to their human capital. ${ }^{11}$ The old, in contrast, normally have substantial financial assets, yet the present value of their future labor earnings (plus pension income) will be relatively small, so they will be net lenders.

\footnotetext{
9 We make use of a standard result here that $A W^{\prime \prime}(A) / W^{\prime}(A)=-\gamma_{i}$ in the equilibrium to such a model.

10 Since $\sum_{i} B_{i t}=0$, market prices must adjust so that $s \sum_{i} H_{i t}=(1-s) \sum_{i} F_{i t}$. As a result, we infer that $0<s<1$.

11 We have assumed perfect capital markets, however. If, due to adverse selection reasons, the bond market works poorly, then young borrowers will face credit constraints. In this case, subsidies to loans can be appropriate on efficiency grounds.
} 
Even if $\gamma_{i}$ is the same for all individuals, note that the size of $s_{i t}$ (and $b_{i t}$ ) conveys information about potential labor income, $H_{i t}$, at least after controlling for the individual's age and the size of current financial assets. In particular, those with high potential labor income will hold more equity and less debt. If the high skilled also have a lower $\gamma_{i}$, as we assume, this relationship is only strengthened.

Allowing for such variation in $\gamma_{i}$ across individuals seems essential in order to make sense of the data on portfolio choice. At least U.S. data ${ }^{12}$ suggest that the rich tend to be large net debtors, while the poor hold a much larger fraction of their financial portfolios in bonds. ${ }^{13}$ Without variation in $\gamma_{i}$, equations (6) and (7) imply that this can occur only if those with high observed labor income tend to have higher values of $H_{i t} / F_{i t}$, at any given age. Yet observed labor income, as a fraction of assets, if anything is lower for the rich than the poor - financial assets are distributed much more unequally than labor income. That $H_{i t}$ consists of the present value of observed labor income plus the present value of leisure implies that the skilled could still have a higher ratio $H_{i t} / F_{i t}$ if they consumed enough more leisure relative to the poor. Yet hours of work do not seem to vary much with the wage rate, while the age of retirement if anything is later for those with high wage rates. If the rich are enough less risk averse, however, then we can make sense of observed portfolio choices.

We have assumed in addition, however, that the degree of risk aversion depends not on observed labor income but on potential labor income. This is consistent, for example, with equity holdings being higher for the educated, even conditional on observed labor income. $^{14}$

Consider now whether, starting from $\mu_{t}=0$, the government would want to raise $\mu_{t}$. To address this question, we first need to assume some explicit objective function for the

\footnotetext{
12 See, for example, the figures in Gordon and Slemrod (1988). Their figures do not control for age. However, the rich inevitably would tend to be older than the poor, so should have been net lenders for this reason if in fact $\gamma_{i}$ were the same for everyone.

13 Until recently, only a small fraction of individuals (primarily the rich) had any equity holdings.

14 For some empirical support for this relationship, see Poterba and Samwick (forthcoming). While they do not control for an individual's wage rate, they do find that more educated individuals hold more equity, even after controlling for a flexible function of both current income (in part as a proxy for tax incentives) and current wealth.
} 
government. In particular, assume that at each date the government chooses $\mu_{t}$ and the function $\tau($.$) to maximize$

$$
\max _{\mu_{t}, \tau}\left[\sum_{i} \int_{s=t}^{\infty} e^{-\rho s} V\left(C_{i s} ; w_{i s}, \mathbf{p}_{s}\right) d s+\lambda \int_{s=t}^{\infty} e^{-r s} \tau_{i s}\left(w_{i s} h_{i s}+\mu_{s} r_{s} B_{i s}\right) d s\right],
$$

where $\lambda$ is the weight put on government revenue. ${ }^{15}$

Starting from $\mu_{t}=0$, a marginal increase in $\mu_{t}$ raises welfare if ${ }^{16}$

$$
\sum_{i} \int_{s}\left(V_{i s}^{\prime}-\lambda\right) B_{i s} \frac{\partial r_{s}}{\partial \mu_{t}} d s>\sum_{i}\left(V_{i t}^{\prime}-\lambda\right) \tau_{i t}^{\prime} r_{t} B_{i t}-\lambda \sum_{i} \int_{s} e^{-r s} \tau_{s}^{\prime} w_{i s} \frac{\partial h_{i s}}{\partial \mu_{t}} d s
$$

Following Saez (2002), consider the impact instead of modifying the structure of the income tax so as to impose the same average tax change on those with each value of labor income, $z \equiv w h$, as occurs when $\mu_{t}$ changes. In particular, consider the impact of the set of tax changes $d \tau(z)=\tau^{\prime}(z) r_{t} \bar{B}(z)$, where $\bar{B}(z)$ is the average value of $B_{i t}$ among those with labor income equal to $z$. Since the nonlinear income tax schedule has simultaneously been chosen to maximize social welfare, we know that these changes in the tax schedule have no net impact on welfare, implying that ${ }^{17}$

$$
\sum_{i} \int_{s}\left(V_{i s}^{\prime}-\lambda\right) B_{i s} \frac{\partial r_{s}}{\partial \tau_{t}} d s=\sum_{i}\left(V_{i t}^{\prime}-\lambda\right) \tau_{i t}^{\prime} r_{t} \bar{B}(z)-\lambda \sum_{i} \int_{s} e^{-r s} \tau_{s}^{\prime} w_{i s} \frac{\partial h_{i s}}{\partial \tau_{t}} d s
$$

Subtracting equation (9) from equation (8), we find that the optimal $\mu_{t}$ is positive if

$$
\begin{gathered}
\sum_{i} \int_{s}\left(V_{i s}^{\prime}-\lambda\right)\left(B_{i s}-\bar{B}(z)\right)\left(\frac{\partial r_{s}}{\partial \mu_{t}}-\frac{\partial r_{s}}{\partial \tau_{t}}\right) d s-\sum_{i}\left(V_{i t}^{\prime}-\lambda\right) \tau^{\prime} r_{t}\left(B_{i t}-\bar{B}(z)\right) \\
+\sum_{i} \int_{s}\left(V_{i s}^{\prime}-\lambda\right) \bar{B}(z)\left(\frac{\partial r_{s}}{\partial \mu_{t}}-\frac{\partial r_{s}}{\partial \tau_{t}}\right) d s>-\lambda \sum_{i} \int_{s} e^{-r s} \tau_{s}^{\prime} w_{i s}\left(\frac{\partial h_{i s}}{\partial \mu_{t}}-\frac{\partial h_{i s}}{\partial \tau_{s}}\right) d s
\end{gathered}
$$

\footnotetext{
15 Here, $\lambda$ implicitly measures the utility gain from the goods and transfer payments financed out of the tax revenue.

16 Note that $\sum_{i} \lambda B_{i t}=0$ since $\sum_{i} B_{i t}=0$.

17 Here, the derivatives with respect to $\tau$ is a shorthand for the effects of the change in the full schedule for $\tau$.
} 
or equivalently if

$$
\int_{s} \sum_{z} \operatorname{cov}\left(V_{i s}^{\prime}, B_{i s} \mid z\right) \frac{\partial r_{s}^{n}\left(z_{i}\right)}{\partial R} d s+\sum_{i} \int_{s}\left(V_{i s}^{\prime}-\lambda\right) \bar{B}(z) \frac{\partial r_{s}}{\partial R} d s>-\lambda \sum_{i} \int_{s} e^{-r s} \tau_{s}^{\prime} w_{i s} \frac{\partial h_{i s}}{\partial R} d s .
$$

Here, $R$ is a shorthand for the combined policy changes in $\mu_{t}$ and $\tau_{t}$, and $r_{s}^{n}\left(z_{i}\right)=r_{s}(1-$ $\left.\mu_{s} \tau^{\prime}\left(z_{i}\right)\right)$.

In the setting of Atkinson and Stiglitz (1976), these combined tax changes would have no net effect on labor supply, so that the right-hand side of equation (11) would equal zero. In addition, given the separability they assume between leisure and consumption, $B_{i t}$ simply depends on $z$, so that the covariance term on the left-hand size equals zero. Their paper does not consider general equilibrium price effects, so that the second term on the right-hand side is ignored. As a result, the optimal $\mu_{t}$ would equal zero.

The setting here is more general than that considered by Atkinson and Stiglitz. To begin with, leisure is a function of time, rather than a scalar. In addition, even if the underlying direct utility function at each date in our model is weakly separable between leisure and consumption, the overall utility function is not in general separable between leisure and consumption. We also allow for both heterogeneity in tastes and general equilibrium price changes.

What then can be said about whether the inequality in equation (11) holds? Consider first the effects of these combined tax changes on labor supply. In general, labor supply can certainly change in response to such a tax reform, and in different directions for net lenders and net borrowers, and differently at different dates. However, it is difficult to say anything in general about the sign of the resulting effect on government revenue. Given the empirical evidence of low elasticities of labor supply, combined with the result in Atkinson and Stiglitz that this term is precisely zero in their setting, we presume that this term will be small relative to the other terms. Any later results, however, must be qualified by the ambiguity concerning the size (and sign) of this term.

Much more can be said about the other two terms. In the first term on the left-hand side, the covariance describes the degree to which observed bond holdings provide information about an individual's underlying ability, even given their observed labor income. If 
the covariance is nonzero, then this information can be used to redesign the tax structure to better approximate a tax on unobserved ability. ${ }^{18}$ Given the assumptions of our model, the more able are less risk-averse, so everything else equal invest less in bonds (or borrow more). In addition, given observed labor income, the more able have higher potential income so by equation (7) would hold fewer bonds. As a result, this covariance term should be positive for all values of $z$. Aiding net lenders at the expense of net borrowers would then imply transfers from the more able to the less able, conditional on observed labor income. The question then is what tax treatment of net interest income accomplishes this. If the $\partial r_{s}^{n}\left(z_{i}\right) / \partial R$ are mostly positive, then this effect provides support for taxing net interest income.

The second term describes the impact on welfare arising from any changes in the market interest rate, even ignoring any heterogeneity in households conditional on observed labor income. If those with low observed income tend to be net lenders and those with high income net borrowers, then an increase in the market interest rate is a distributional gain. Starting from $\mu_{t}=0$, introducing portfolio distortions has no efficiency cost at the margin (ignoring impacts on labor supply), so that the resulting changes in the interest rate can provide distributional gains with no offsetting efficiency costs. In contrast, further use of the income tax to redistribute from rich to poor implies offsetting efficiency costs that are large enough starting from the optimal tax structure to yield no net gain. ${ }^{19}$ If $\partial r_{s} / \partial R>0$, then this term provides support for taxing interest income.

To proceed further, we need information about the signs of $\partial r_{s} / \partial R$ and $\partial r_{s}^{n}\left(z_{i}\right) / \partial R$. If we divide equation (5) through by $\gamma_{i} \sigma^{2}$, weight by $A_{i s}$ and sum over $i$, we find that

$$
\sum_{i}\left[\frac{A_{i s} g-\left(1-\mu_{s} \tau_{i s}^{\prime}\right) r_{s} A_{i s}}{\gamma_{i} \sigma^{2}}\right]=\sum_{i} S_{i s}=\sum_{i} F_{i s} .
$$

Consider first the impact of the policy changes on interest rates at date $t$. At date $t$, changes in $\tau_{t}^{\prime}$ have no impact on $r_{t}$, when evaluated at $\mu_{t}=0$. What about $\partial r_{t} / \partial \mu_{t}$ ? If

\footnotetext{
18 Saez (2002) has made this point in a more general context.

19 This is just the intuition developed in Naito (1999) in a different context.
} 
we differentiate the market-clearing condition at date $t$ with respect to $\mu_{t}$ and evaluate at $\mu_{t}=0$, we find that

$$
\frac{1}{r_{t}} \frac{\partial r_{t}}{\partial \mu_{t}}=\frac{\sum_{i} \tau_{i t}^{\prime} A_{i t} / \gamma_{i}}{\sum_{i} A_{i t} / \gamma_{i}}
$$

This expression is a weighted average of the $\tau_{i t}^{\prime}$, with the rich and the less risk averse getting more weight. As a result, this weighted average tax rate should be close to the top marginal tax rate. Denote this weighted average tax rate by $\tau_{w t}^{\prime}$.

Since $0<\tau_{w t}^{\prime}<1$, it immediately follows that $\partial r_{t} / \partial \mu_{t}>0$. Therefore the second term in equation (11) at date $t$ is positive.

What about $\partial r_{t}^{n}\left(z_{i}\right) / \partial \mu_{t}$, evaluated at $\mu_{t}=0$ ? Since by definition $r_{t}^{n}\left(z_{i}\right)=\left(1-\mu_{t} \tau_{i t}^{\prime}\right) r_{t}$, we find that $\partial r_{t}^{n}\left(z_{i}\right) / \partial \mu_{t}=\left(\tau_{w t}^{\prime}-\tau_{i t}^{\prime}\right) r_{t}$. Therefore, $\partial r_{t}^{n}\left(z_{i}\right) / \partial \mu_{t}>0$ for all investors with $\tau_{i t}^{\prime}<\tau_{w t}^{\prime}$, and conversely. Given that $\tau_{w t}^{\prime}$ should be close to the top marginal tax rate, we infer that $\partial r_{i t}^{n} / \partial \mu_{t}$ is positive except for the richest individuals; almost all investors should face an increased after-tax interest rate, and more so the lower the $\tau_{i t}^{\prime}$ they face, when net interest income is made taxable/tax deductible.

As a result, unless the covariance in the first term on the left-hand side of equation (11) is much larger for those with high observed labor income than for other individuals, ${ }^{20}$ this first term at date $t$ is also positive.

What about changes in interest rates at future dates? The only potential impact on future interest rates of policy changes at date $t$ arises from changes in savings, so in the $A_{i s}$ caused by these combined tax changes. These impacts, arising from a marginal tax change during a brief time period $d t$ are necessarily of second order. We can therefore ignore them.

Together, these results imply that the optimal value of $\mu_{t}$ is in fact positive, consistent with observed tax structures. Evaluated at $\mu_{t}=0$, there are no marginal efficiency costs due to portfolio distortions arising from a marginal change in $\mu_{t}$, since portfolios are allocated efficiently when $\mu_{t}=0$. As $\mu_{t}$ increases, portfolio distortions and the resulting

20 This covariance equals the correlation between $V_{i t}^{\prime}$ times the standard deviations of both $B_{i t}$ and $V_{i t}^{\prime}$. There is no reason to expect the size of the correlation to differ systematically with ability level. While the standard deviation of $B_{i t}$ should be an increasing function of income, the standard deviation of $V_{i t}^{\prime}$ should plausibly be much larger among those with low reported labor income. As a result, there is no clear presumption about how the size of this covariance varies across income levels. 
efficiency losses grow. At the optimal value of $\mu_{t}$, these marginal efficiency losses just offset the marginal distributional gains from including an additional fraction of net interest income in the tax base. In particular, at the optimal value of $\mu_{t}{ }^{21}$

$$
\sum_{i}\left(\tau_{i t} r_{t}+\mu_{t} \frac{\partial r_{t}}{\partial \mu_{t}}\right) B_{i t}\left(\lambda-V_{i t}^{\prime}\right)+\sum_{i} V_{i t}^{\prime} B_{i t} \frac{\partial r_{t}}{\partial \mu_{t}}=-\lambda \sum_{i} \mu_{t} \tau_{i t}^{\prime} r_{t} \frac{\partial B_{i t}}{\partial \mu_{t}}
$$

The right-hand side of this equation measures the marginal efficiency (and revenue) loss from increasing the fraction of net interest income included in the tax base. As emphasized for example in Gordon and Slemrod (1988), the revenue loss from the resulting tax arbitrage can be very large. At the margin, the loss from increased arbitrage as $\mu_{t}$ increases just offsets the gains described above. ${ }^{22}$

\section{Conclusions}

Why is interest income taxed so much more heavily than other forms of capital income? This differential tax treatment of bonds vs. other assets has generated substantial use of debt to reduce overall tax payments, through the rich borrowing from the poor to invest in more lightly taxed assets. The result is substantially lower tax revenue, sizable efficiency costs, and apparently net gains to rich borrowers and net losses to poor lenders, together suggesting that this tax treatment makes no sense on welfare grounds.

We reexamine this argument more formally, and find that taxes on net interest income can well be justified within an optimal tax framework. To begin with, the forecasted increase in the market interest rate results in a redistribution from rich borrowers to poor lenders. Yet this redistribution comes at no marginal efficiency cost, starting from a situation with no distortions to portfolio choice, so at the margin dominates further redistribution through the income tax.

In addition, information about an individual's portfolio choice can potentially reveal information about her earnings ability, even controlling for observed labor income. We

21 For simplicity of notation, we ignore here the feedback onto labor supply.

22 Note, however, that at higher values of $\mu_{t}$ portfolios become more unequal, with the rich borrowing more and the poor lending more. This implies that the marginal distributional gains also grow as $\mu_{t}$ increases. 
presume that those with higher potential income will be less risk averse, and so invest relatively more heavily in equity than those with lower potential income, even holdings observed income fixed. By making use of this extra information about earnings ability, the tax system can be better tailored to redistribute from able to less able, for any given efficiency cost. Given the sizable forecasted increase in the market interest rate in response to a tax on net interest income, this tax does aid low-ability lenders at the expense of more able borrowers. 


\section{REFERENCES}

Atkinson, Anthony and Joseph Stiglitz. 1976. "The Design of Tax Structure: Direct vs. Indirect Taxation," Journal of Public Economics 6, pp. 55-75.

Besley, Timothy and Costas Meghir. 1998. "Tax Based Savings Incentives," mimeo.

Gordon, Roger H. 1985. "Taxation of Corporate Capital Income: Tax Revenues versus Tax Distortions," Quarterly Journal of Economics 100, pp. 1-27.

Gordon, Roger H. and Joel Slemrod. 1988. "Do We Collect any Revenue from Taxing Capital Income?" Tax Policy and the Economy 2, pp. 89-130.

Merton, Robert C. 1990. Continuous-Time Finance. Cambridge: Blackwell.

Mirrlees, James A. 1971. "An Exploration in the Theory of Optimal Income Taxation," Review of Economic Studies 38, pp. 175-208.

Naito, Hisahiro. 1999. "Re-examination of Uniform Commodity Taxes under a NonLinear Income Tax System and Its Implications for Production Efficiency," Journal of Public Economics 71, pp. 165-88.

Poterba, James M. and Andrew A. Samwick. forthcoming. "Taxation and Household Portfolio Composition: U.S. Evidence from the 1980's and 1990's," Journal of Public Economics.

Saez, Emmanuel. 2002. "The Desirability of Commodity Taxation under Non-Linear Income Taxation and Heterogeneous Tastes," Journal of Public Economics 83, pp. 217-30.

U.S. Department of the Treasury. 1984. Tax Reform for Fairness, Simplicity, and Economic Growth. Washington, D.C.: U.S. Government Printing Office. 